\title{
ARTICLE
}

\section{Evidence of decreased gap junction coupling between astrocytes and oligodendrocytes in the anterior cingulate cortex of depressed suicides}

\author{
Arnaud Tanti ${ }^{1}$, Pierre-Eric Lutz $\mathbb{I D}^{1,3}$, John Kim ${ }^{1}$, Liam O'Leary ${ }^{1}$, Jean-François Théroux ${ }^{1}$, Gustavo Turecki (D) $^{1,2}$ and Naguib Mechawar ${ }^{1,2}$
}

Glial dysfunction is a major pathophysiological feature of mood disorders. While altered astrocyte (AS) and oligodendrocyte-lineage $(\mathrm{OL})$ functions have been associated with depression, the crosstalk between these glial cell types has never been assessed in that context. AS are potent regulators of myelination, in part through gap junction (GJ) channels formed by the heterotypic coupling of AS-specific (Cx30 and Cx43) and OL-specific (Cx32 and Cx47) connexins. This study therefore aimed at addressing the integrity of AS/OL coupling in the anterior cingulate cortex (ACC) of depressed suicides. Using immunofluorescence and confocal imaging, we characterized the distribution of $\mathrm{Cx30}$ and mapped its expression onto OL somas, myelinated axons, and brain vasculature in postmortem brain samples from depressed suicides $(N=48)$ and matched controls $(N=23)$. Differential gene expression of key components of the GJ nexus was also screened through RNA-sequencing previously generated by our group, and validated by quantitative real-time PCR. We show that Cx30 expression localized onto OL cells and myelinated fibers is decreased in deep cortical layers of the ACC in male-depressed suicides. This effect was associated with decreased expression of OL-specific connexins, as well as the downregulation of major connexin-interacting proteins essential for the scaffolding, trafficking, and function of GJs. These results provide a first evidence of impaired AS/OL GJ-mediated communication in the ACC of individuals with mood disorders. These changes in glial coupling are likely to have significant impact on brain function, and may contribute to the altered $\mathrm{OL}$ function previously reported in this brain region.

Neuropsychopharmacology (2019) 44:2099-2111; https://doi.org/10.1038/s41386-019-0471-z

\section{INTRODUCTION}

Glial dysfunction is a pathophysiological hallmark of depression. Postmortem studies have consistently shown changes in astrocyte (AS) numbers and morphology, as well as in the expression of astrocytic markers in fronto-limbic regions of depressed individuals [1-10], while pharmacological or genetic disruption of AS function in rodents has been associated with depressive-like behavior [11, 12]. More recently, oligodendrocyte-lineage (OL) cells, which allow for a formidable form of brain plasticity by responding to environmental cues and experiences in an activitydependent manner [13-15], were also found to display functional impairments in both postmortem brain samples from depressed individuals [16-24] and animal models mimicking some aspects of depression following stress exposure [25-27]. This could represent a neurobiological substrate to the altered connectivity and white matter integrity that have been reported in imaging studies [28-35], highlighting that myelin plasticity in discrete corticolimbic areas could mediate some of the behavioral changes characterizing depression or modulate individual vulnerability to this mood disorder.

While ASs and OLs have both been independently implicated in the pathophysiology of depression, their interplay has never been examined in this context. ASs are potent regulators of OL cell proliferation, survival, maturation, and myelination [36-39], in part through cytosolic exchanges allowed by GJ coupling between ASs and OLs $[36,38,40,41]$. The docking of two connexin hexamers from two adjacent cells forms a channel allowing the exchange of a wide range of small molecules such as ions, metabolites, second messengers, and neurotransmitters [42]. ASs mainly express connexin $30(\mathrm{Cx} 30)$ and connexin $43(\mathrm{Cx} 43)$, while oligodendrocytes mainly express connexin 32 (Cx32) and connexin 47 (Cx47). Functional channels are formed between ASs and OLs through the heterotypic coupling of Cx30-Cx32 and Cx43-Cx47 [41, 43-47], and this glial GJ coupling is critical for OL function, including normal myelination [48-51].

Our group and others recently reported that the expression of both genes coding for astrocytic Cx30 (GJB6) and Cx43 (GJA1) is decreased in multiple areas of the depressed suicide brain [7, 52]. These findings were replicated in animal models mimicking some aspects of depression following stress exposure [53, 54]. The underlying mechanisms and functional consequences of such coupling changes are unclear, but given the widespread functions of astroglial networks [38,55-57], alterations in glial coupling are likely to have significant consequences on brain function.

\footnotetext{
${ }^{1}$ McGill Group for Suicide Studies, Douglas Mental Health University Institute, McGill University, Montreal, QC, Canada and ${ }^{2}$ Department of Psychiatry, McGill University, Montreal, QC, Canada

Correspondence: Naguib Mechawar (naguib.mechawar@mcgill.ca)

${ }^{3}$ Present address: Centre National de la Recherche Scientifique, Institut des Neurosciences Cellulaires et Intégratives, CNRS UPR 3212, Université de Strasbourg, Fédération de
} Médecine Translationnelle de Strasbourg, Strasbourg, France

Received: 25 April 2019 Revised: 23 July 2019 Accepted: 26 July 2019

Published online: 2 August 2019 
Table 1. Subjects characteristics

\begin{tabular}{|c|c|c|c|c|c|c|}
\hline & \multicolumn{3}{|c|}{ Gene expression } & \multicolumn{3}{|c|}{ Immunofluorescence } \\
\hline & Controls & Depressed suicides & Sig. & Controls & Depressed suicides & Sig. \\
\hline $\mathrm{N}$ & 23 & 48 & - & 13 & 26 & - \\
\hline Axis 1 diagnosis & 0 & MDD (40); DD-NOS (8) & - & 0 & MDD (21); DD-NOS (5) & - \\
\hline History of CA & 0 & 25 & - & 0 & 14 & - \\
\hline Age (years) & $46.2 \pm 22.2$ & $45.6 \pm 13.2$ & n.s & $33.4 \pm 11.6$ & $40.1 \pm 11.7$ & n.s \\
\hline $\operatorname{Sex}(M / F)$ & $18 / 5$ & $38 / 10$ & - & $13 / 0$ & $26 / 0$ & - \\
\hline PMI (hours) & $35.4 \pm 21.5$ & $46.4 \pm 26$ & n.s & $27.3 \pm 13.8$ & $37 \pm 19.4$ & n.s \\
\hline $\mathrm{pH}$ & $6.5 \pm 0.3$ & $6.6 \pm 0.3$ & n.s & $6.5 \pm 0.2$ & $6.5 \pm 0.3$ & n.s \\
\hline RIN & $6.9 \pm 0.6$ & $6.6 \pm 0.7$ & n.s & NA & NA & n.s \\
\hline Substance dependence & 0 & 17 & - & 0 & 11 & - \\
\hline Antidepressant medication & 0 & 17 & - & 0 & 6 & - \\
\hline
\end{tabular}

Importantly, it remains to be determined whether decreased expression of astrocytic connexins may reflect changes in GJ coupling of ASs among themselves, and/or with other cell types.

We examined this question by investigating AS/OL coupling in postmortem anterior cingulate cortex (ACC) samples from depressed suicides and matched controls. This region was selected because we previously found it to display convergent molecular and cellular abnormalities of OL function in depressed suicides [18], particularly in individuals with a history of child abuse (CA). Based on these results and evidence suggesting that such individuals may represent a distinct clinical and neurobiological subtype of depression [58], we also examined samples from a group of depressed suicides with a history of CA. We used confocal microscopy to map the expression of the AS connexin Cx30, focusing on layers 5-6 of the ACC, because both densities of OLs and myelinated fibers are known to be higher in these deeper cortical layers [59-61]. We provide evidence of a significant decrease of Cx30 immunoreactivity specifically localized onto OLlineage cells and myelinated fibers, as well as impaired gene expression of OL-specific connexins and key GJ-related genes in the ACC of depressed suicides, altogether suggesting impaired AS/OL GJ communication in the brain of depressed suicides.

\section{MATERIAL AND METHODS}

Human postmortem samples

This project was approved by the Douglas Hospital Research Ethics Board. Samples were obtained from the Suicide section of the Douglas-Bell Canada Brain Bank (Douglas Hospital Research Centre, Montreal, Canada) in collaboration with the Quebec Coroner's Office and with informed consent from next of kin. Samples were obtained from individuals having died by suicide in the context of a depressive episode (depressed suicides-DS; $N=48$ ) and from psychiatrically healthy controls (controls-CTRL; $N=23$ ) having died suddenly. Presence of any or suspected neurological/ neurodegenerative disorder signaled in clinical files constituted an exclusion criterion. Sample size was chosen based on sample availability and according to previous studies from our group. Groups were matched for age, postmortem interval (PMI), tissue $\mathrm{pH}$ and RNA Integrity Number (RIN) (Table 1). Cases and controls were defined with the support of medical charts and Coroner records, and based on previously described and validated psychological autopsies [62]. Proxy-based interviews with one or more informants best acquainted with the deceased are supplemented with information from archival material obtained from hospitals, Coroner's office and social services. Clinical vignettes are then produced and assessed by a panel of clinicians to generate DSM-IV diagnostic criteria, providing sociodemographic characteristics, social developmental history, DSM-IV axis I diagnostic information and behavioral traits; information that is obtained through different adapted questionnaires, such as SCID-I (Axis I disorders), SCID-II (personality disorders), and Childhood Experience of Care and Abuse (CECA) [63, 64]. The data presented in Table 1 indicates current substance dependence and prescribed antidepressant medication, validated postmortem by toxicological assessments. Histological experiments for $\mathrm{Cx} 30$ quantification and colocalization were performed in male subjects only, on a subset of matched controls and depressed suicides (Table 1).

Tissue dissections

ACC samples were dissected from frozen coronal sections with the guidance of a human brain atlas [65]. Histology blocks $\left(\sim 1 \mathrm{~cm}^{3}\right)$ were collected in sections equivalent to plate $6(-30 \mathrm{~mm}$ from the center of the anterior commissure) immediately rostral to the genu of the corpus callosum, using the cingulate and the callosal sulci as the rostral and caudal landmark limits, respectively. Frozen blocks were fixed overnight in 10\% formalin, cryoprotected in $20 \%$ sucrose/PBS, and cut in 50- $\mu$ m-thick sections with a cryostat. Sections were kept in cryoprotectant (30\% glycerol, 30\% ethylene glycol, PBS) until processed for immunofluorescence.

\section{Immunohistochemistry}

Free-floating sections were incubated overnight at room temperature with primary antibodies diluted in a solution of PBS $/ 0.3 \%$ Tx-100/2\% normal donkey serum, rinsed and incubated for $2 \mathrm{~h}$ at room temperature with Alexa-488, Сy3 or Cy5-conjugated secondary antibodies. Sections were mounted on slides, coverslipped (Vectashield mounting medium with DAPI, Vector Laboratories) and kept at $4{ }^{\circ} \mathrm{C}$ until imaging. Primary antibodies, their respective dilutions, and matching secondary antibodies are listed in Table S1. Cx30 immunoreactivity was validated by ensuring that no signal was found when omitting the primary antibody or replacing the antibodies with an isotype control. Expected immunoreactivity was confirmed by co-staining $\mathrm{C} \times 30$ and C43, confirming their partially overlapping distribution (Fig. 1c). Adequate antibody penetration was assessed by comparing $\mathrm{C} \times 30$ puncta densities throughout the thickness of the sections (Fig. S1A), and controlling for possible changes in 
A

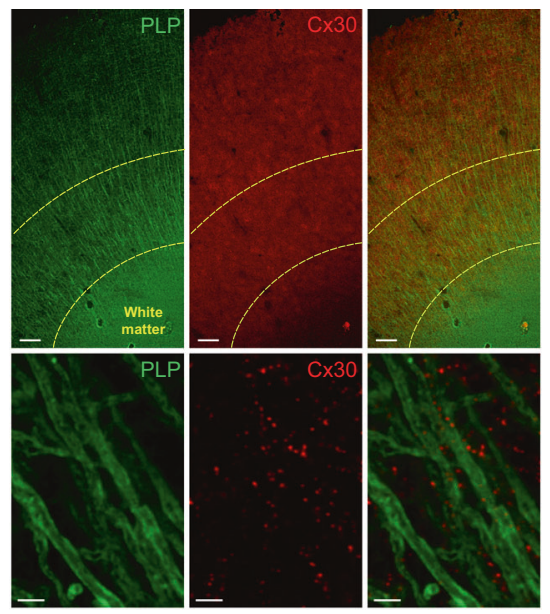

B

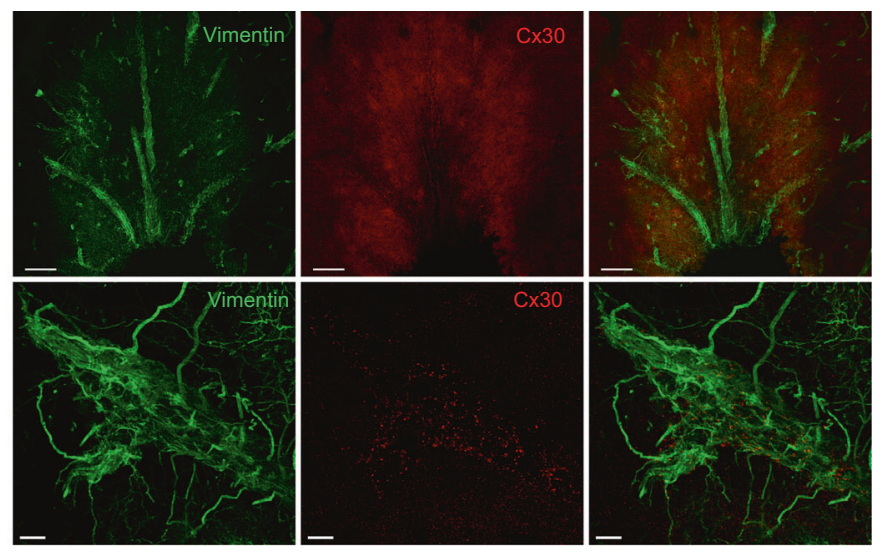

C

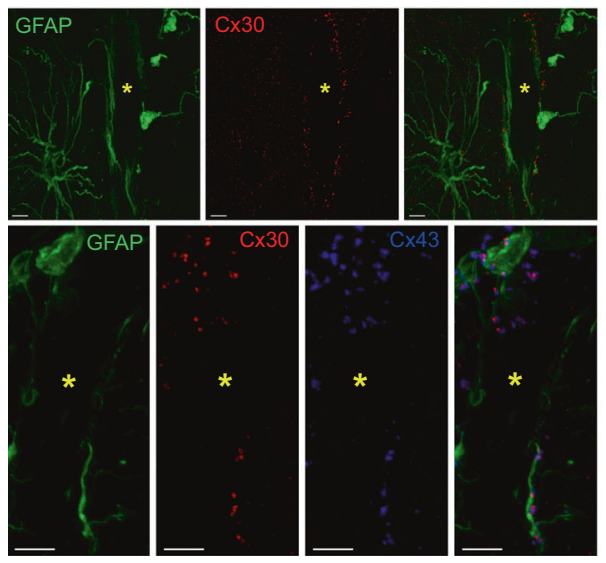

Fig. 1 Distribution of connexin 30 immunoreactivity in the human anterior cingulate cortex. a Cx30 (red) at low (top panels) and high (bottom panels) magnification shows a strong level of expression in cortical gray matter but virtually no expression in deep white matter, with characteristic puncta-like immunoreactivity enriched in the neuropil. Myelin Proteolipid Protein (PLP) (green) was used to delineate white matter and visualize myelinated fibers. The area between dashed lines corresponds to deep cortical layers (layers 5-6) in which further quantification was performed. Cx30 surrounds and colocalizes with myelinated axons in cortical gray matter. Scale bars $=200 \mu \mathrm{m}$ (top) and $2 \mu \mathrm{m}$ (bottom). b Connexin 30 (red) is heavily enriched along brain vasculature and perivascular endfeet of astrocytes stained with vimentin (green). Maximum intensity Z projection at high magnification (bottom panels) shows strong colocalization of Cx30 puncta along blood vessels and perivascular endfeet, consistent with previous description of Cx30 distribution in the brain. Scale bars = $100 \mu \mathrm{m}$ (top) and $10 \mu \mathrm{m}$ (bottom). c Top panel shows the enrichment of Cx30 puncta labeling (red) along Glial fibrillary acidic protein (GFAP+) astrocytic endfeet (green) lining a blood vessel $\left.{ }^{*}\right)$. Bottom panel shows another blood vessel surrounded by GFAP+ astrocytic fibers and perivascular endfeet (green), with strong colocalization of Cx30 and Cx43 (blue), as expected from the literature. Scale bars $=5 \mu \mathrm{m}$

tissue thickness (Fig. S1B), which may indicate tissue degradation. Cx30 expression localized onto OLs and myelinated fibers was visualized by combining Cx30 staining with either Nogo-A, a reliable marker of OL somas, and Myelin Proteolipid Protein (PLP), a major myelin component. Cx30 expression localized onto blood vessels was visualized by combining $\mathrm{C} \times 30$ staining with Laminin, a marker of the basal lamina. For illustration purposes, Glial Fibrillary Acidic Protein (GFAP) was combined to these markers to visualize ASs. The different combinations of primary and secondary antibodies used in our study are indicated in Table S1.

Confocal imaging and analysis

Images were acquired on an Olympus laser-scanning confocal microscope (FV1200). Stack images were taken with a $\times 60$ objective $(\mathrm{NA}=1.42)$ and 3.5 digital zoom, with $\mathrm{XY}$ pixel width of $0.06 \mu \mathrm{m}$, and $Z$ spacing of $0.8 \mu \mathrm{m}$. This spacing was chosen to prevent any dot from being counted twice in two successive $Z$ slices, while minimizing the number of dots that would be missed between two slices (Fig. S2). Parameters were kept consistent across acquisitions. For $\mathrm{Cx} 30$ density measurements, four stacks with an average of 15 Z-sections per stack were semirandomly acquired within layer $5 / 6$ of the ACC. We imaged through the whole mounted thickness of the tissue, defining top, and bottom as $Z$ coordinates where signal started to fade. The analysis was performed on all the slices obtained after removing three slices from the top and bottom $Z$ positions for each stack, considered as guard zones, to rule out inconsistencies in fluorescence and cutting artefacts. Average mounted thickness of the tissue was compared between groups to ensure even Z sampling (Fig. S1B). For each Z-section, Cx30 puncta were quantified by the find maxima function of ImageJ with a noise tolerance of 350 , and divided by the image area to calculate a density per $\mathrm{mm}^{2}$. We used this approach as it gave the most accurate estimate of puncta number compared with manual counting on a small set of captured images (Fig. S1C, $R^{2}=0.98, P<0.0001$ ). For each stack, the Z-sections densities were averaged, and stack averages computed per subject to yield final Cx30 puncta densities. We ensured that the intraindividual variability in Cx30 densities 
between stacks was in line with common standards in stereology and low enough (Fig. S1D, coefficient of error $~ 5 \%$ ) to assume that sampling variability would neither mask nor drive differences between groups.

For Cx30 localized onto Nogo-A+ cells, an average of 20 cells were manually segmented within three successive images stacks acquired within layer $5 / 6$ of the ACC. For each Z-section, cell selection was enlarged by $0.5 \mu \mathrm{m}$, and number of $\mathrm{C} \times 30$ puncta quantified using the find maxima function with a noise tolerance of 350. The approach is illustrated in Fig. S3, showing different examples of contoured Nogo-A+ cells, based on Nogo-A immunoreactivity, and Cx30 puncta localizing within Nogo-A+ cells enlarged boundaries. This approach was used to include Cx30 puncta either colocalizing or immediately adjacent to Nogo$\mathrm{A}+$ cells, as true co-colocalization may prevent the inclusion of Cx30 puncta juxtaposed to Nogo-A+ cells. Total Cx30 puncta numbers per cell were averaged to yield the average number of Cx30 localized onto Nogo-A+ cells per subject. Cx30 localized onto myelinated fibers and blood vessels was performed similarly in four stacks taken within layer $5 / 6$ of the ACC. For each Z-section, PLP, or Laminin immunoreactivity were subjected to autothresholding and converted to mask. A median filter with a 3 pixels radius was applied, followed by a round of dilation and erosion. For each Z-section the number of Cx30 puncta within PLP or Laminin masks was then quantified using the find maxima function (noise tolerance of 350), and the density of $\mathrm{C} \times 30$ calculated by dividing the number of $\mathrm{C} \times 30$ puncta by PLP or Laminin area, respectively. Figs. S4 and S5 show examples of masking of PLP+ fibers and Laminin + blood vessels. As per the quantification of $\mathrm{C} \times 30$ puncta localized onto Nogo-A+ cells, this approach was used so that rather than colocalization per se, $\mathrm{Cx} 30$ puncta was considered as "mapping" onto PLP+ fibers and Laminin+ blood vessels when either colocalizing or directly juxtaposed to these structures. Densities per stack were then averaged to yield the final density of Cx30 localized onto PLP or Laminin per subject. All imaging and analyzes were performed blind to experimental group.

\section{RNA-sequencing}

The RNA-sequencing dataset, which was generated with a cohort including all of the subjects from the present study, was prepared, analysed and thoroughly described in a report we recently published [18]. In brief, total RNA was extracted from frozen ACC samples and a 2100 Bioanalyzer (Agilent) used to measure RNA concentration and RIN. Libraries were prepared at the Genome Quebec Innovation Center with the TrueSeq Stranded Total RNA Sample Preparation kit (Illumina) and sequenced on an Illumina HiSeq 2000 (100 bp paired-end), with 62 million reads/library. Differential expression between groups was analyzed with DESeq2 using RIN, age and sex as covariates. All of these steps were performed previously [18], and the present study used this dataset to screen differential expression in a panel of genes built based on the literature and the evidence of their role in GJ signaling and cell-cell junctions [42, 66-75] (Fig. 4).

\section{RT-PCR validation}

Validation of differential gene expression was performed by quantitative RT-PCR for the eight following genes: Gap Junction Protein Beta 6 (GJB6), Gap Junction Protein Alpha 1 (GJA1), Gap Junction Protein Beta 1 (GJB1), Gap Junction Protein Gamma 2 (GJC2), Caveolin-1 (CAV1), Caveolin-2 (CAV2), Occludin (OCLN), and Drebrin 1 (DBN1) (Table S2). Starting from $50 \mathrm{mg}$ of frozen tissue, total RNA was extracted using the RNeasy Lipid Tissue Mini Kit (Qiagen) with DNase digestion. RNA quantity and RIN were measured with the 2200 TapeStation (Agilent), and only samples with RIN $>5.5$ were used for analysis. One microgram of RNA was used to synthetize cDNA using M-MLV reverse transcriptase (Invitrogen) with oligo-dT and random hexamers. Quantitative PCR reactions were performed using SYBR Green intercalating dye and master mix (Biorad) on a QuantStudio 6 Flex Real-Time PCR system (ThermoFisher Scientific), using four replicates per gene. Primers were designed with Primer-BLAST (http://www.ncbi.nlm.nih.gov/ tools/primer-blast/) and validated by dissociation curves and gel migration. Relative expression was calculated on the QuantStudio Real-Time PCR Software version 1.2 (ThermoFisher Scientific) using calibration curves and normalization by the housekeeping gene GAPDH.

\section{Statistics}

Analyses were performed on Statistica version 12 (StatSoft), SPSS version 20 (IBM Corp.), and Prism version 6 (GraphPad Software). Distribution and homogeneity of variances were assessed with Shapiro-Wilk and Levene's tests, respectively. When more than two groups were compared, group effects were detected with Kruskal-Wallis nonparametric one-way ANOVAs, followed by Dunn's multiple comparisons post hoc test. Analysis of Covariance (ANCOVA) was used to control for the possible contribution of age, PMI, $\mathrm{pH}$, antidepressant medication, and substance dependence on the differences observed between Controls and Depressed Suicides in Cx30 puncta densities localized onto Nogo-A + cells, PLP + fibers, and Laminin + blood vessels, using group (MDD/suicide) as the independent factor. Differential expression in the RNA-sequencing dataset was performed using DEseq2, using a linear model controlling for RIN, age, PMI, and sex. Possible contributions of confounding factors for the RT-PCR data was assessed using backward stepwise linear regressions, with a removal level of $P>0.1$, to select the most parsimonious set of factors including age, $\mathrm{PMI}, \mathrm{pH}, \mathrm{RIN}$, substance dependence, antidepressant medication, sex, and group (MDD/suicide) significantly predicting the dependent variable. Nominal $p$-values are reported with a significance threshold set at 0.05 .

\section{RESULTS}

General distribution and validation of $\mathrm{Cx} 30$ immunostaining We first sought to characterize the general distribution of $\mathrm{Cx} 30$ in the ACC and validate antibody specificity. As expected [76, 77], Cx30 immunoreactivity took the form of a very dense and clear punctate labeling highly enriched in cortical gray matter neuropil (Fig. 1a), while virtually absent in adjacent white matter. Since Cx30 is known to strongly associate with cerebral vasculature, where ASs establish numerous GJs at the perivascular endfeet [77-80], we combined immunostainings for Cx30, vimentin, and GFAP to confirm this distributional pattern. Vimentin was chosen because it is an intermediate filament expressed by cells in blood vessels walls as well as by a subpopulation of ASs [81]. The distribution of $\mathrm{C} \times 30$ was homogenous throughout cortical layers, and as illustrated in Fig. 1b, Cx30 immunoreactivity was particularly enriched along AS endfeet lining blood vessels in highly vascularized areas. We further addressed the specificity of this distribution by immunostaining for GFAP together with both AS-specific connexins, $\mathrm{C} \times 30$ and $\mathrm{C} \times 43$. As shown in Fig. 1C and previously reported in rodents $[45,78,80]$, Cx30 and Cx43 highly colocalized at the level of GFAP+ endfeet along blood vessels. We then quantified the overall density of $\mathrm{Cx} 30$ puncta in the ACC of controls and depressed suicides, segregating cases based on their known history of CA (Fig. 2a). We found no difference between groups (Kruskal-Wallis ANOVA: $\mathrm{H}(20,23)=0.3268, \quad P=0.84$ ), regardless of the history of $C A$, as both depressed suicides with (DS-CA) and without (DS-nCA) history of CA showed Cx30 puncta densities similar than controls. This was unlikely to be attributable to cofounding factors, as the density of $\mathrm{C} \times 30$ puncta was not correlated with age nor PMI (PMI vs Cx30 puncta density: $R^{2}=$ $0.01, P=0.63$; Age vs $C \times 30$ puncta density: $R^{2}=0.05, P=0.33$; Fig. $2 d$, e). Because previous studies have linked antidepressant medication and alcohol abuse to changes in the expression of 
A

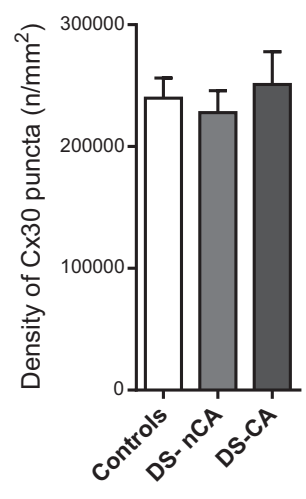

B

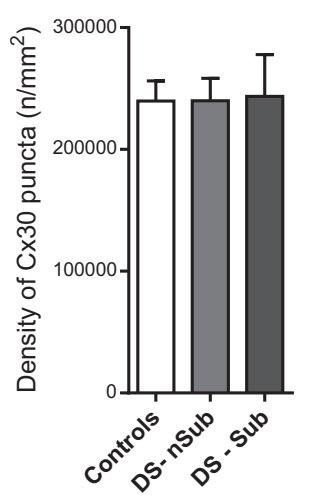

C

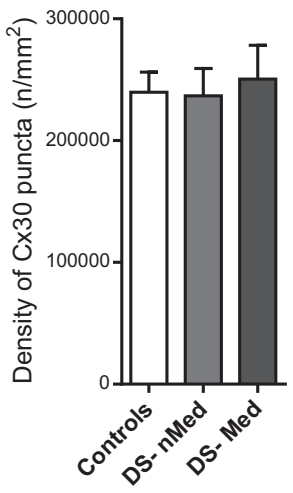

D

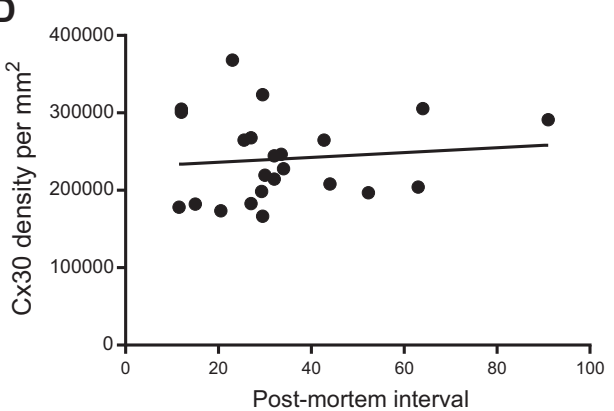

E

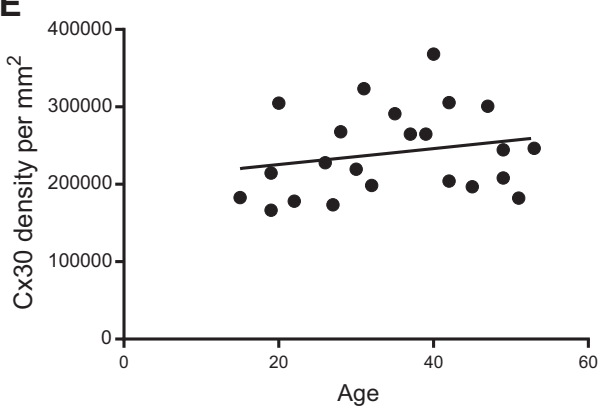

Fig. 2 Depressed Suicides show no change in the density of $C \times 30$ puncta compared with controls in the anterior cingulate cortex. a Density of total Cx30 puncta in the ACC of depressed suicides without (DS-nCA, $N=5)$ or with (DS-CA, $N=7)$ a history of child abuse and Controls $(N=$ $11)$. No difference between groups was found (Kruskal-Wallis ANOVA: $\mathrm{H}(2,23)=0.3268, P=0.84)$. b No effect of substance abuse was found on the density of Cx30 in depressed suicides. Depressed suicides without (DS-nSub, $N=7$ ) or with (DS-Sub, $N=5$ ) a history of substance abuse showed similar densities of $\mathrm{Cx30}$ compared with controls $(N=11)$ (Kruskal-Wallis ANOVA: $\mathrm{H}(2,23)=0.02247, P=0.99)$. c Previous medication with antidepressants had no effect on the densities of Cx30 in the ACC. Depressed suicides without (DS-nMed, $N=8)$ or with (DS-Med, $N=4)$ a known antidepressant prescription the last 3 months before death showed similar densities of $\mathrm{C} \times 30$ compared with controls $(N=11)$ (Kruskal-Wallis ANOVA: $\mathrm{H}(2,23)=0.3308, P=0.85)$. $\mathbf{d}$ No correlation between $\mathrm{Cx} 30$ puncta densities and postmortem interval $(P=0.63)$ or $\mathbf{e}$ age $(P=0.33)$ was found, indicating overall that the absence of changes in Cx30 puncta density between cases and controls is likely not linked to covariables. Data represent mean \pm s.e.m

astrocytic connexins [52, 82], we compared Cx30 puncta densities in cases with or without known history of substance abuse (Fig. 2b), as well as cases with or without known antidepressant prescription during the last 3 months before death (Fig. 2c). No significant effect of substance abuse (Kruskal-Wallis ANOVA: $\mathrm{H}(2,23)=0.02247, P=0.99)$ or medication (Kruskal-Wallis ANOVA: $\mathrm{H}(2,23)=0.3308, P=0.85)$ was found, supporting the notion that, at least in the ACC, overall Cx30 puncta density is not altered as a function of psychopathology, medication, or comorbid substance abuse.

Decreased Cx30 localized onto OL cell bodies and myelinated fibers in depressed suicides

Because of the very high level of Cx30 expression and puncta labeling, small differences in Cx30 associated with specific cell-cell interactions could go unnoticed, while assessing overall $\mathrm{C} \times 30$ distribution and density in the tissue. Since Cx30 is involved in AS/ OL GJs both at the soma and onto myelinated fibers [41], we quantified Cx30 puncta localized onto OLs and myelinated fibers to address possible changes specific to AS/OL coupling (Fig. 3a). Using Nogo-A as a reliable marker of mature OLs $[19,83]$, we first quantified the number of $\mathrm{C} \times 30$ puncta localizing onto individual NogoA + cells in layers $5 / 6$ of the ACC (Fig. 3b, c). Although the average localization of $\mathrm{C} \times 30$ onto individual mature OLs was relatively low, we found a significant difference between groups (Kruskal-Wallis ANOVA: $\mathrm{H}(2,23)=9.09, P<0.05)$, with decreased Cx30 puncta localized onto Nogo-A+ cells in depressed suicides compared with controls, regardless of history of CA (Dunn's multiple comparisons tests: CTRL vs DS-nCA and CTRL vs DS-CA: $P<0.05)$. These differences were also unlikely to be biased by group differences in Nogo- $A+$ cells areas $(F(2,19)=0.47, P=0.63$; Fig. S6).

To tease out the potential contribution of confounding factors to this effect we used an ANCOVA, comparing Controls and Depressed Suicides regardless of their history of CA, since it did not have an effect on Cx30 puncta density localized onto Nogo-A + cells, and adjusting for the potential effects of PMl, age, $\mathrm{pH}$, substance abuse, and antidepressant medication (Fig. 3d and Table S3). We found that none of those covariates had a significant effect (Table S3), while group still was significantly associated with decreased $\mathrm{C} \times 30$ puncta localized onto Nogo-A + cells $(F(1,23)=$ $7675, P=0.014$; effect size $d=-1.34$; Fig. $3 d$ ), suggesting that OLs somas show reduced coupling with ASs in depressed suicides.

We then combined Myelin PLP and Cx30 immunofluorescence to quantify the density of $\mathrm{C} \times 30$ puncta localized onto myelinated fibers (Fig. 3e, f). In accordance with decreased AS/OL coupling at the soma, we also found differences between groups (Kruskal-Wallis ANOVA: $\mathrm{H}(2,27)=7.471, \quad P<0.05)$, with $\mathrm{C} \times 30$ puncta decreased along PLP+ myelinated fibers in depressed suicides regardless of history of $C A$, although differences were more statistically robust in DS-CA (Dunn's multiple comparison test, CTRL vs DS-CA: $P<0.05)$, as only a trend was detectable between DS-nCA and controls (Dunn's multiple comparison test, CTRL vs DS-nCA: $P<0.1)$. Densities of $C \times 30$ puncta localized onto $\mathrm{PLP}+$ myelinated axons were however similar between DS-CA and DS-nCA (Dunn's multiple comparison test, DS-nCA vs DS-CA: $P=$ 
A

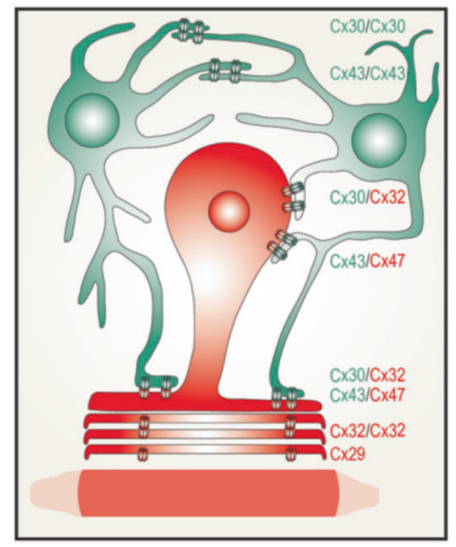

B

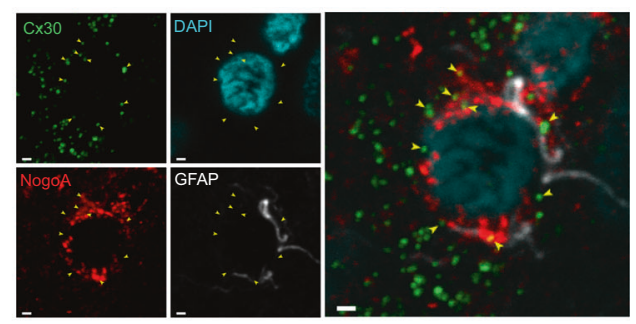

E

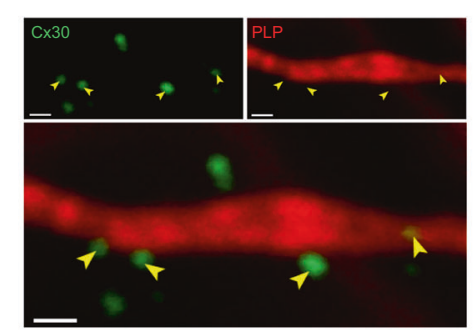

H

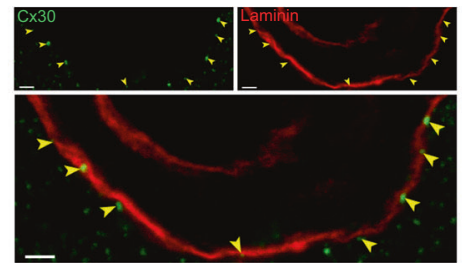

C

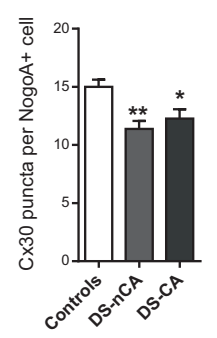

$\mathbf{F}$
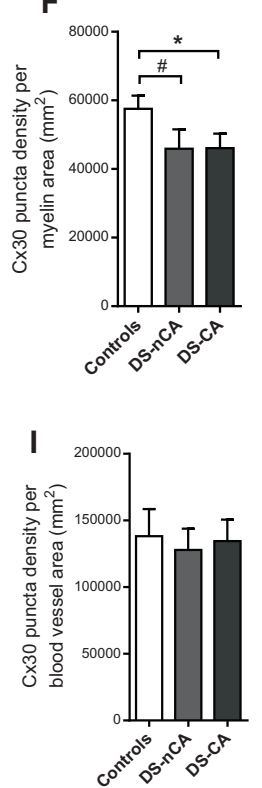

G

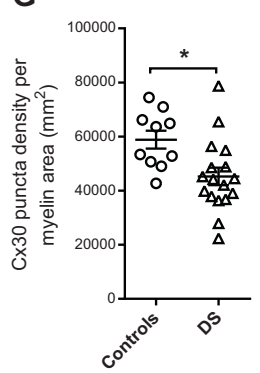

D

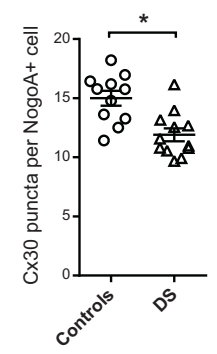

$\mathbf{J}$

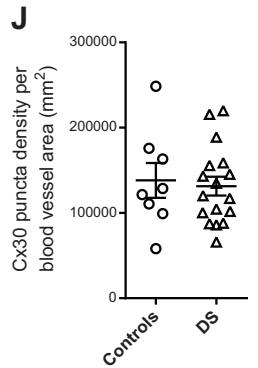

Fig. 3 Specific decrease in Cx30 puncta localized onto oligodendrocytes and myelinated fibers in the anterior cingulate of depressed suicides. a Drawing illustrating astrocyte-oligodendrocyte (AS/OL) GJ coupling at the soma and around myelinated axons through heterotypic pairing of $\mathrm{Cx} 30$ or Cx43 on the astrocyte (colored in green) side, with Cx32 and Cx47, respectively on the oligodendrocyte (colored in red) side. Adapted from Orthmann-Murphy et al. [47]. b Changes in AS/OL pairing between controls and depressed suicides was first addressed through quantification of Cx30 puncta (green) localized onto oligodendrocytes cells bodies stained with Nogo-A (red). Some Cx30 immunoreactivity is found surrounding oligodendrocytes cells bodies and colocalizing in this example with GFAP+ astrocytes (gray). Arrowheads point to Cx30 puncta specifically localized onto Nogo-A+ cells (see Fig. S4). Scale bar $=1 \mu \mathrm{m}$. c Depressed suicides, regardless of history of child abuse, showed a decrease in Cx30 puncta localized onto Nogo-A + oligodendrocytes (Kruskal-Wallis ANOVA: H(2,23) $=9.09, P<0.05$; Dunn's multiple comparisons tests: Controls $(N=11)$ vs DS-nCA $(N=5)$ and Controls vs DS-CA $(N=7), P<0.05)$. d Because history of CA had no effect on Cx30 puncta localized onto NogoA + cells, we pooled both depressed suicides groups to address the potential contribution of confounding factors on changes observed between Controls $(N=11)$ and Depressed Suicides $(N=12)$. After controlling for age, PMI, pH, substance dependence, and antidepressant medication, group (MDD/suicide) was still found to be the only significant factor (Table S3), with Depressed Suicides showing decreased $C \times 30$ puncta localized onto Nogo-A + cells $(F(1,23)=7675, P=0.014)$. e Changes in $A S / O L$ pairing between controls and depressed suicides was also assessed though quantification of $\mathrm{C} \times 30$ puncta (green) localized onto myelinated axons visualized with Myelin Proteolipid Protein (PLP, red). Arrowheads indicate Cx30 puncta directly considered as localized onto PLP fibers, based on the approach described in Fig. S5. Scale bar $=0.5 \mu \mathrm{m}$. f We found differences between groups (Kruskal-Wallis ANOVA: $\mathrm{H}(2,27)=7.471, P<0.05)$, with $\mathrm{Cx} 30$ puncta densities decreased along PLP+ myelinated fibers in depressed suicides regardless of history of CA, although differences were more statistically robust in DS-CA (Dunn's multiple comparison test, Controls $(N=10)$ vs DS-CA $(N=11)$ : $P<0.05)$, as only a trend was detectable between DS-nCA and controls (Dunn's multiple comparison test, Controls vs DS-nCA $(N=6): P<0.1$ ). Densities of $C \times 30$ puncta localized onto $\mathrm{PLP}+$ myelinated axons were however similar between DS-CA and DS-nCA (Dunn's multiple comparison test, DS-nCA vs DS-CA: $P=0.99$ ). g Because history of CA had no effect on Cx30 puncta density localized onto PLP+ fibers, we pooled both depressed suicides groups to address the potential contribution of confounding factors on changes observed between Controls $(N=10)$ and Depressed Suicides $(N=17)$. After controlling for age, PMI, pH, substance dependence, and antidepressant medication, group (MDD/suicide) was still found to be the only significant factor (Table S4), with Depressed Suicides showing decreased Cx30 puncta density localized onto PLP+ fibers $(F(1,27)=5.755, P=$ 0.026). $\mathbf{h}$ To address the specificity of the observed changes in Cx30 puncta localized onto OL cells or myelinated fibers, we measured Cx30 puncta (green) density localized onto blood vessels stained with laminin (red). Arrowheads point to Cx30 puncta directly considered as localized onto blood vessels, based on the approach described in Fig. S6. Scale bar $=2 \mu \mathrm{m}$. i Changes in Cx30 puncta localization seem specific to AS/OL GJ coupling since no change between groups (Controls, $N=8$; DS-nCA, $N=8$; DS-CA, $N=9$ ) was observed in Cx30 puncta (green) localized onto blood vessels stained with laminin (red) (Kruskal-Wallis ANOVA: $H(2,25)=0.2, P=0.9$ ). $\mathbf{j}$ After controlling for age, PMI, $\mathrm{pH}$, substance dependence, and antidepressant medication, group (MDD/suicide) was still not found to be affecting Cx30 puncta density localized onto blood vessels (Table $\mathrm{S} 5, \mathrm{~F}(1,25)=0.003, P=0.960$ ). Scale bar $=2 \mu \mathrm{m}$. ${ }^{*} P<0.05 ;{ }^{* *} P<01 ; \#, 0.05<P<0.1$ (versus Controls). Data in represent mean \pm s.e.m 
A

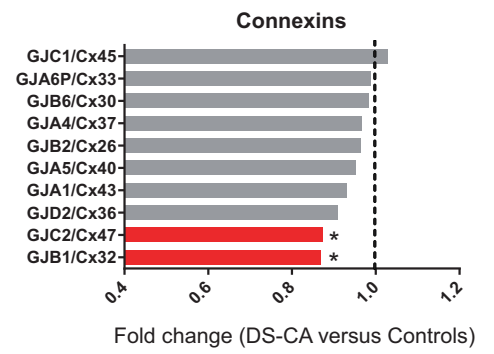

Connexin binding

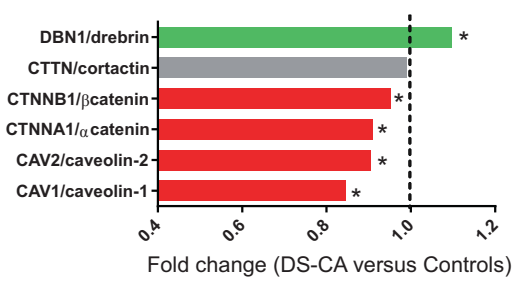

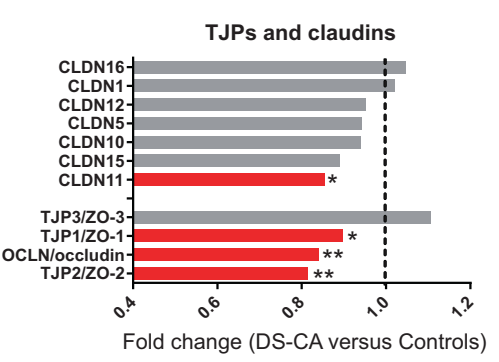

Spectrins

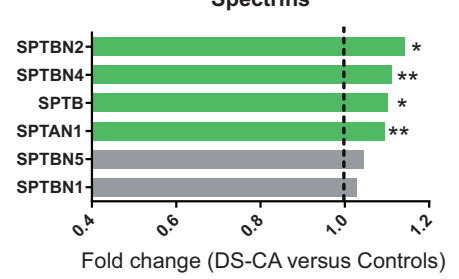

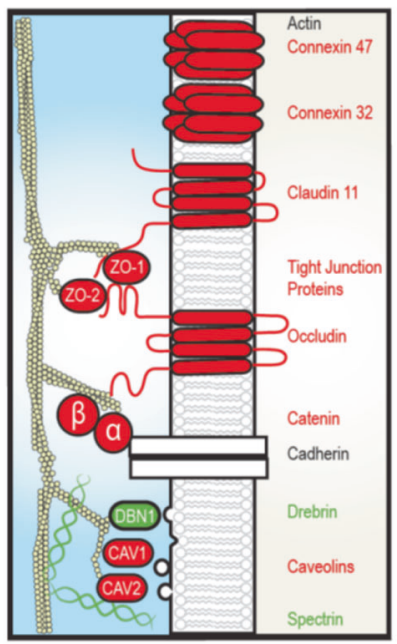

B

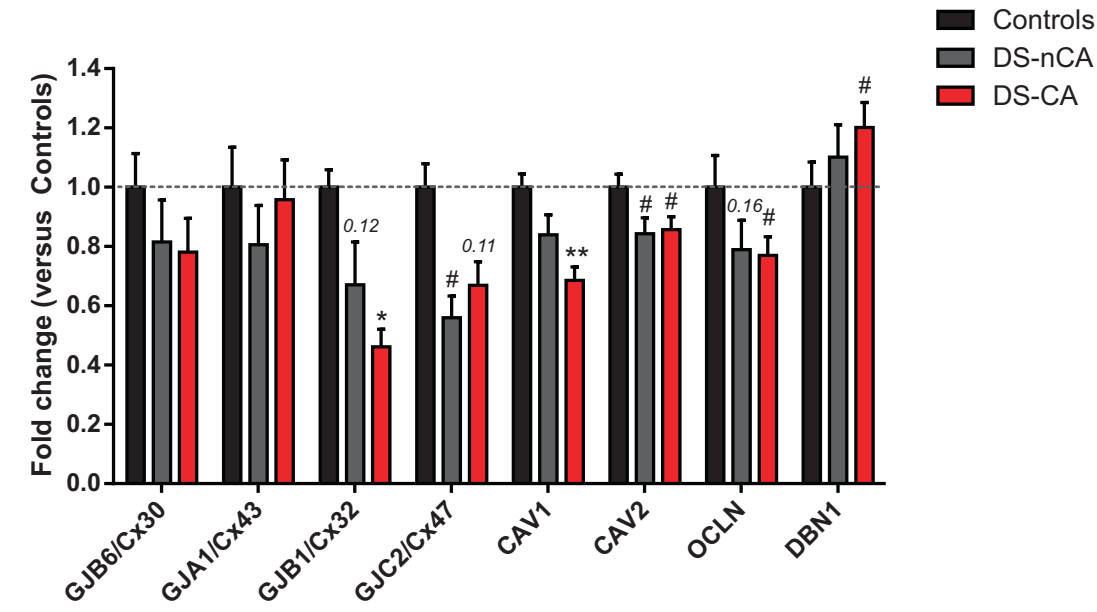

C

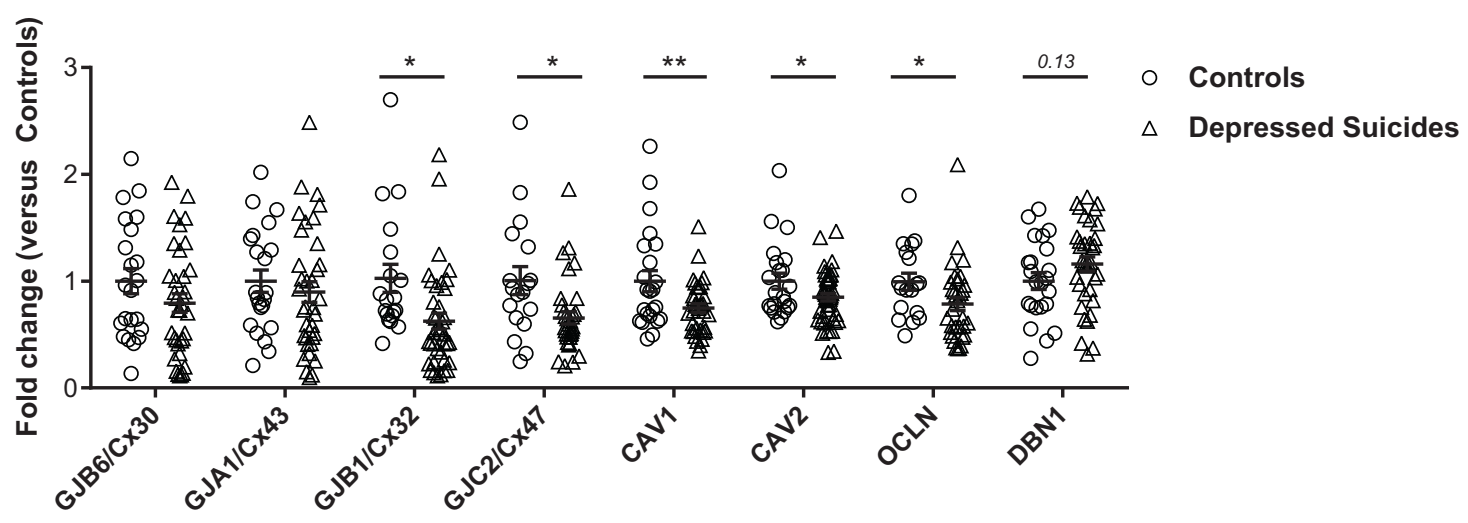

0.99). We also addressed whether these changes were possibly driven by confounding factors using an ANCOVA (Fig. $3 \mathrm{~g}$ and Table S4), testing the effect of group (MDD/suicide) adjusting for PMI, age, pH, substance abuse, and antidepressant medication. None of these covariates had a significant impact on our dependent variable (Table S4), while depressed suicides still showed decreased $\mathrm{C} \times 30$ puncta density localized onto PLP+ fibers after controlling for cofactors $(F(1,27)=5.755, P=0.026$; effect size $d=-1.12$; Fig. 3g).
To rule out the possibility that these group differences may be driven by intraindividual variability in $\mathrm{C} \times 30$ densities associated with our sampling of Nogo-A + cells and PLP+ fibers, we applied a bootstrapping approach to both datasets. For both experiments, we generated 10,000 new datasets in which, for each subject, individual averages were computed after random resampling with replacement. $P$-values from the resulting 10,000 group comparisons were highly enriched below significance threshold (Fig. S7), further validating our approach by suggesting that intraindividual 
Fig. 4 Genes involved in the scaffolding, trafficking, and function of gap junction channels and cell-cell junctions are differentially expressed in the anterior cingulate cortex of depressed suicides. a RNA-sequencing results comparing samples from the anterior cingulate cortex of depressed suicides with a history of child abuse vs controls were screened to probe the differential expression of a literature-based list of genes related to GJ channel scaffolding and function. We found that among genes coding for major connexins, depressed suicides showed a downregulation specifically for the two oligodendrocyte-specific connexins Cx32 (GJB1) and Cx47 (GJC2). Major tight junction proteins (TJPs) such as occluding (OCLN), zona occludens-1 and -2 (TJP1/ZO-1 and TJP2/ZO-2), as well as claudin-11/OSP (CLDN11), an essential component of myelin interlamellar tight junctions were also found to be downregulated in depressed suicides. Genes coding for connexins-binding partners and regulators of GJ-mediated intercellular communication, such as caveolin-1 and -2 (CAV1 and CAV2) and alpha/beta catenins (CTNNA1 and CTNNB1) were also found to be downregulated. Of note, several genes coding for actin-binding proteins thought to bridge connexins to actin microfilament cytoskeleton, such as drebrin (developmentally regulated brain protein, DBN1) and spectrins were found to be collectively upregulated in depressed suicides compared with controls. Red and green bars indicate significant downregulation and upregulation, respectively, while gray bars indicate no significant change in gene expression. The drawing on the right depicts the suggested interactions between these different components of the GJ nexus and connexin-interacting proteins, adapted from Dbouk et al. [70]. Red and green indicate components found to be downregulated or upregulated, respectively, in the RNA-sequencing dataset. b Because the RNAsequencing dataset was generated comparing samples from controls and depressed suicides with a history of child abuse (DS-CA), a subset of these differentially expressed genes was selected for validation with quantitative RT-PCR and adding a third group of depressed suicides with no history of child abuse (DS-nCA). Globally and consistent with the RNA-sequencing results, DS-CA subjects showed a downregulation of Cx32/GJB1, Cx47/GJC2, CAV1 and CAV2, OCLN, and an upregulation of DBN1 (Controls $(N=16-23)$ vs DS-CA $(N=19-25),{ }^{*} P<0.05,{ }^{* *} P<0.01$, $\left.{ }^{\#} P<0.1\right)$, although these results were not as statistically robust as observed in the RNA-sequencing dataset. Importantly these changes did not seem specific to a history of child abuse, as no significant difference was found between DS-CA and DS-nCA for any of these genes, while DSnCA showed similar trends towards decreased expression of Cx32/GJB1, Cx47/GJC2, CAV2, and OCLN (Controls ( $N=16-23)$ vs DS-nCA ( $N=$ $\left.12-24),{ }^{\#} P<0.1\right)$. c Since changes in gene expression were not found to be specific to a history of child abuse, we combined both depressed suicides groups to increase our statistical power and perform backward stepwise linear regressions and tease out the contributions of confounding variables in differential gene expression (Tables S6-S13). Depressed Suicides showed significant downregulations of oligodendrocyte connexins Cx32/GJB1 and Cx47/GJC2, CAV1 and CAV2 as well as OCLN (Controls $(N=16-23)$ vs Depressed Suicides $(N=$ 33-48), ${ }^{*} P<0.05$, $\left.{ }^{*} P<0.01\right)$. The upregulation of $D B N 1$ observed in the RNA-seq dataset was however not validated, although a small trend towards increased expression was detectable (Controls $(N=23)$ vs Depressed Suicides $(N=36), P=0.13)$. Data represent mean \pm s.e.m. TJPs tight junction proteins, GJB6 gap junction protein beta 6 (Cx30), GJA1 gap junction protein alpha 1 (Cx43), GJB1 gap junction protein beta 1 (Cx32), GJC2 gap junction protein gamma 2 (Cx47), CAV1 Caveolin 1, CAV2 Caveolin 2, OCLN Occludin, DBN1 Drebrin

variability in Cx30 measurements is unlikely to confound our results.

Finally, to address whether changes in Cx30 puncta distribution could also be observed between ASs and other cell types, we used a similar approach to assess the Cx30 immunoreactivity associated with cerebral vasculature immunolabeled for laminin (Fig. 3h, i). Unlike what was observed on Nogo-A + cells and PLP+ axons, the density of $\mathrm{Cx30}$ puncta localized along laminin + blood vessels was similar between groups (Kruskal-Wallis ANOVA: $\mathrm{H}(2,25)=0.2$, $P=0.9$ ). Also, none of the covariates nor group (MDD/suicide) ( $F$ $(1,25)=0.003, P=0.960)$ had a significant effect on $C \times 30$ puncta localized onto blood vessels (Fig. $3 \mathrm{j}$ and Table S5). These results highlight that changes in Cx30-mediated GJ coupling in the ACC of depressed suicides may be specific to AS/OL communication.

Downregulation of OL-specific connexins and scaffolding components of GJs in the ACC of depressed suicides Changes in GJ coupling are likely to involve transcriptomic alterations of genes essential for the synthesis of GJ components, their scaffolding, trafficking, and function. To complement our histological approach, we screened the gene expression of some key regulators of the GJ proteome from a previously published RNA-sequencing dataset comparing a group of control subjects to matched depressed suicides with a history of CA in the ACC [18], using a general linear model with age, sex, PMI, and RIN as covariates. This dataset had allowed us to find a global downregulation of OL-related genes, as well as morphometric impairments of myelin in depressed suicides with a history of CA. Here, a nonexhaustive literature-based list of genes [42, 66$74,84-87$ ] was screened that included major connexins and some of their known binding partners (Fig. $4 \mathrm{a}, \mathrm{b}$ ). The latter included zona occludens 1 (TJP1/ZO-1), ZO-2 (TJP2), and ZO-3 (TJP3), spectrins, drebrin (DBN1), and catenins, which together form a network of proteins that bridges connexins to microfilaments and microtubules and interact with occludins, claudins, and cadherins to form junctional nexuses $[42,66,68,70,74]$.

Among connexin genes, only those coding for two OL-specific connexins, Cx32 (GJB1), and Cx47 (GJC2), were downregulated in depressed suicides $(P<0.05)$. These connexins are binding partners of the AS-specific connexins Cx30 and Cx43, respectively, which pair together to form functional GJs between ASs and OLs $[41,43]$. Moreover, two major connexin-interacting proteins, alpha- and beta-catenins [72, 88] (CTNNA1 and CTNNB1), both adherens junction components, were also downregulated in cases versus controls $(P<0.05)$. Several major cytoskeletal components essential for the scaffolding of GJs and junctional nexus were also found to be differentially expressed. The major tight junction proteins ZO-1 (TJP1) and ZO-2 (TJP2), interacting with each other and with connexins to regulate GJ plaque size and distribution $[66,67,71]$, were downregulated in samples from depressed suicides $(P<0.05$ for $Z O-1$ and $P<0.01$ for $Z O-2)$. We also screened for other core proteins of tight junctions, such as occluding (OCLN) and claudins, which are also part of the junctional nexus, some of which co-immunoprecipitate with the OL-expressed Cx32 [75, 87]. Again, occludin $(O C L N)$ was significantly downregulated in depressed suicides $(P<0.01)$, while among the claudin family of proteins, the only member found to be differentially expressed between groups was CLDN11 (claudin-11, $P<0.05$ ), an essential component of myelin interlamellar tight junctions [89-91], also suggesting that cell-cell junctions involving OLs may be particularly impaired in depressed suicides.

Caveolin-1 (CAV1) and Caveolin-2 (CAV2), major regulators of connexin trafficking and assembly, as well as GJ-mediated intercellular communication [85, 92], were also found to be downregulated in depressed suicides $(P<0.05)$. Of the key actinbinding proteins important to bridge connexins to actin microfilament cytoskeleton [69, 73, 86, 93, 94], DBN1 (developmentally regulated brain protein, drebrin, $P<0.05$ ), SPTAN1 (Alpha-II Spectrin, $P<0.01$ ), SPTB (beta-I spectrin, $P<0.05$ ), SPTBN2 (betaIII spectrin, $P<0.05$ ), and SPTBN4 (Beta-IV Spectrin, $P<0.01$ ) were all upregulated in depressed suicides compared with controls. Finally, to highlight the biological relevance of this literaturebased list of genes, we performed permutation testing to show that our list is significantly enriched in differentially expressed genes (15/33) compared with genome wide frequency (3734/ 20893) (Fig. S8, $P=0.01$ ).

A subset of these genes was selected for validation with quantitative RT-PCR. We focused on the connexins enriched in ASs 
(Cx30 and $\mathrm{Cx} 43)$ and OLs (Cx32 and Cx47) as well as CAV1, CAV2, $O C L N$, and $D B N 1$ (Fig. 4c, d), because robust evidence was supporting that these directly interact with connexins and are involved in GJ function [75, 85-87, 92, 95]. Importantly, because in our RNA-sequencing study all depressed suicides had a history of $C A$, which may specifically lead to $\mathrm{OL}$ abnormalities, $\mathrm{PPCR}$ validation was performed in controls and in both DS-nCA and DS-CA groups similarly to our histological experiments, to clarify whether observed changes were associated with psychopathology or specific to history of CA. Overall, regardless of CA, depressed suicides displayed a general downregulation of $\mathrm{C} \times 32$, Cx47, CAV1, and CAV2 as well as OCLN expression and an upregulation of $D B N 1$ expression compared with controls (Fig. 4c). These changes were however not as statistically robust as previously observed using RNA-seq.

Importantly, because these changes did not seem specific to a history of CA, we combined both depressed suicides groups (Fig. 4d) to perform linear regression analysis and tease out the possible contribution of confounding factors on changes in gene expression observed in depressed suicides, including sex, antidepressant medication, substance abuse, PMI, RIN, $\mathrm{pH}$, and age. Because the number of factors included in the model are subsequent in view of our modest sample size, we used a backward stepwise regression model with a removal level of $P>$ 0.1 to select the most parsimonious set of covariates predicting the dependent variable. For each gene of interest, statistics for the full models including all factors as well as the best predicting and most parsimonious models are displayed in Table S6-S13.

Overall, the results of these regressions are in accordance with the RNA-seq results. We found that group (MDD/suicide) was not a significant predictor for the expression of both AS-specific connexins GJB6/Cx30 (Table S6) and GJA1/Cx43 (Table S7), while both OL-specific connexins $\mathrm{Cx} 32(\beta=-0.269, \mathrm{t}(55)=-2.068, p=$ 0.043; effect size $d=-0.77$; Table S8) and Cx47 $(\beta=-0.316, \mathrm{t}$ $(1,50)=-2.353, P=0.023$; effect size $d=-0.78$; Table S9), as well as CAV1 $(\beta=-0.341, \mathrm{t}(3,56)=-2.908, P=0.005$; effect size $d=$ -0.71 ; Table S10), CAV2 $(\beta=-0.238, \mathrm{t}(2,68)=-2.106, P=0.039$; effect size $d=-0.51$; Table S11), and $\operatorname{OCLN}(\beta=-0.334, \mathrm{t}(2,47)=$ $-2.544, P=0.014$; effect size $d=-0.61$; Table 512 ) were best predicted by group (MDD/suicide), in particular all these genes were downregulated in depressed suicides (Fig. 4c). Changes in DBN1 expression (Table S13), however, were not validated.

\section{DISCUSSION}

In this study, we asked whether AS/OL communication could be impaired in depressed suicides, as previous evidence had linked changes in the expression of astrocytic connexins as well as myelin and $\mathrm{OL}$ function impairments in this population. We characterized the distribution of $\mathrm{C} \times 30$ in the human postmortem ACC, and found that Cx30 immunoreactivity is selectively decreased around somas of mature OLs and along myelinated fibers in depressed suicides, suggesting that AS/OL Cx30mediated coupling may be disrupted. This was supported by the reduced expression of genes coding for the two major OLspecific connexins, $\mathrm{C} \times 32$ and $\mathrm{C} \times 47$, which upon pairing with the astrocytic connexins $\mathrm{C} \times 30$ and $\mathrm{C} \times 43$ allow the formation of functional GJs between these two glial cells. Additional key components of the GJ proteome and cell-cell junctions, in particular components essential for the scaffolding, trafficking, and function of GJs, were also found to be downregulated. Altogether, these results highlight that glial cell communication through cell-cell junctions may be an important feature of the pathophysiology of depression, possibly bridging the cumulative evidence of ASs and OLs abnormalities previously observed in this population.

Several postmortem studies, including from our group, consistently reported decreased expression of astrocytic connexins in frontal regions of suicides. Ernst et al. found both $\mathrm{Cx} 30$ and $\mathrm{Cx} 43$ to be strongly downregulated in the dorsolateral prefrontal cortex of suicides [96]. Nagy et al. further showed that this occurred in other cortical and subcortical brain regions, namely the prefrontal, primary motor and visual cortex, dorsomedial thalamic nucleus, and caudate nucleus [7]. Finally, Miguel-Hidalgo et al. also reported decreased $\mathrm{C} x 43$ expression in the orbitofrontal cortex of depressed individuals [52]. We were therefore surprised that this result was not replicated in our cohort, perhaps highlighting a regional specificity of the ACC with regards to astrocytic changes associated with psychopathology. This discrepancy was also unlikely to be driven by confounding factors such as PMI, age, $\mathrm{pH}$, substance dependence, or antidepressant medication. In agreement, other canonical markers of ASs previously found to be downregulated in BA8/9 of depressed suicides, alongside astrocytic connexins, were not affected in the ACC, such as Aldehyde Dehydrogenase 1 Family Member L1 (ALDH1L1), Glutamine Synthetase (GLUL), and SOX9, a transcription factor previously shown to bind to and potently regulate Cx30 expression [96]. Since AS connexins are engaged in a wide range of GJs between ASs and other cell types, we hypothesize that ASs dysfunction may not be a critical pathophysiological feature in the ACC, but that their interaction with other cell types may be still be compromised through changes occurring in some of their interacting partners. In that scenario whole levels of $\mathrm{C} \times 30$ expression may not be indicative of discrete changes occurring in other cell types. We were particularly interested in AS/OL communication, as we previously showed that cortical myelination is critically impaired in the ACC of depressed suicides [18].

While only representing a small fraction of the $\mathrm{Cx} 30$ immunoreactivity, we found that Cx30 mapping onto mature OLs and myelinating fibers, but not cerebral vasculature, is selectively decreased in depressed suicides. Accordingly, gene expression of the canonical partner of $\mathrm{C} \times 30$ on the $\mathrm{OL}$ side, $\mathrm{C} \times 32$, was also downregulated. Taken together, these observations strengthen our interpretation that $\mathrm{AS} / \mathrm{OL}$ coupling may be impaired in depression, possibly through changes occurring in OLs. Interestingly, the other OL-specific connexin, Cx47, which associates with Cx43, was also downregulated. Although we did not map the distribution of $\mathrm{Cx} 43$ onto OLs and myelinated fibers, this suggests that AS/OL GJ-coupling impairment may not be specific to $\mathrm{C} \times 30$ mediated GJs but likely extend to $\mathrm{C} \times 43-\mathrm{C} \times 47$ pairing as well. While we focused on AS/OL coupling, it would be interesting to use this approach to explore other cell-cell interactions, in particular OL/ OL coupling through homotypic pairing of $\mathrm{C} \times 32$ and $\mathrm{C} \times 47$, both of which are downregulated in the ACC of depressed suicides.

To our knowledge, mapping connexin expression in situ onto different cell types in a psychiatric context has never been done in postmortem brain tissue, in which immunofluorescence can be challenging to perform. This strategy has some limitations, however. Given the limited resolution of confocal microscopy, it is impossible to infer whether the decreased localization of Cx30 to OLs and myelinated fibers represents a loss of $\mathrm{C} \times 30$ pairing to its partner $\mathrm{C} \times 32$ or changes in hemichannel trafficking. While a more direct approach consisting in visualizing the colocalization of Cx30 with $\mathrm{C} \times 32$ onto OLs or their interaction by coimmunoprecipitation would have certainly allowed a more precise assessment of AS/OL coupling, this proved challenging in our hands because of antibodies incompatibility. Also, while we show evidence that our group differences are not likely driven by intraindividual variability in Cx30 densities within our sampled areas, a more systematic sampling could provide further depth to our analysis. Despite this limitation, our immunohistological approach was supported by strong evidence showing impaired expression of key components of the GJ proteome. Alongside reduced expression of the two OL connexins Cx32 and Cx47, major cytoskeletal-scaffolding components and regulators of $\mathrm{GJ}$ trafficking and assembly showed a collective downregulation. 
While some of those are major tight and adherens junction proteins, such as occludin, ZO-1 and ZO-2, or claudin-11, strong evidence highlights their role in supporting the scaffolding and function of GJs $[66,69,70]$. Alongside our observed changes in actin-binding proteins bridging connexins to cytoskeletal microfilaments, such as spectrins and catenins, this hints towards a convergent disruption of the structural integrity of cell-cell junctions. In view of our immunohistological results and reduced expression of $\mathrm{C} \times 32$ and $\mathrm{C} \times 47$, we hypothesize that this may reflect disruptions of GJ integrity, although it is likely that such global effects may translate in other cell-cell junctions, in particular tight and adherens junctions. Tight junctions make up the radial component of CNS myelin, acting as an interlaminar diffusion barrier and structural support [97]. The fact that claudin-11, the major component of OL tight junctions [90], was the only member of the claudin family to be differently expressed in depressed suicides suggests that transcriptional changes associated with psychopathology are particularly prominent in OLs.

Of the possible upstream causes and mechanisms that could underlie disrupted AS/OL GJ connectivity in depressed suicides, neuroinflammation is an interesting candidate [98-100]. Several proinflammatory molecules are thought to alter the composition and structure of tight junctions by modulating some of their key components such as occludin, claudins, and zona occludens proteins [102-103], thereby affecting their permeability and function. This has been documented in the CNS, and disruption of blood-brain barrier integrity through alterations in tight junctions has recently emerged as an interesting pathophysiological feature of depression [104]. With regards to connexins and GJ integrity, chronic inflammation, microglial activation, and astrogliosis have also been associated with $\mathrm{C} \times 32$ and $\mathrm{C} \times 47$ downregulation, and widespread loss of OL/OL and O/A GJs [105-109]. Notably, loss of Cx32 GJs at OL cells bodies and along myelinated fibers in gray matter were previously reported in multiple sclerosis [108], similar to our observations showing decreased Cx30 puncta localized onto OL cell bodies and myelinated axons. Given that increased microglia/macrophage activity has been reported in the ACC of depressed suicides [99], the present evidence of cell-cell junctions and altered AS/OL communication may represent a consequence of depressionassociated low-level chronic neuroinflammation.

We recently reported a robust downregulation of the $\mathrm{OL}$ transcriptome and decreased myelination in the ACC of depressed suicides [18]. Remarkably, these effects were associated with a history of severe CA, but were absent in a matched sample of depressed suicides without history of CA. The present study provides evidence that altered AS/OL communication in the ACC may be a common neurobiological feature of major depression, irrespective of history of early-life adversity, and could possibly be linked to the characteristic changes in ACC volume and function described in depressed patients [31, 110, 111].

Our study however has several limitations, some of which are inherent to a postmortem design and could be addressed by follow-up studies. First, a drawback of our design lies in the fact that our cases are all individuals who died by suicide, preventing us from deciphering the respective contribution and possible interactions between psychopathology, history of abuse, and suicide. Also, despite confidence in our psychological autopsies, using additional phenotypic traits and clinical variables to further refine our findings is statistically difficult with our modest sample size. We also cannot rule out that, because presence or absence of substance abuse and medication in our study was defined postmortem by toxicological assessment, previous history of antidepressant treatment or substance dependence could affect our results. Second, there is increasing and now compelling evidence suggesting that the molecular signature of depression diverges between males and females [113-114], and that trajectories of development and vulnerability to stress and psychopathology show sex-specific features [116-118]. Given that the ratio of male to female suicides is $\sim 4: 1$ in North America, our cohort is predominantly composed of male samples, which prevents proper analysis of whether our results can be generalized or show any kind of sex-specificity. This is a relevant question since sexual dimorphism has been shown in several aspects of glial cell biology [120-122]. Finally, by focusing our cellular analysis on deeper cortical layers of the ACC, it remains unclear whether the changes observed in Cx30 interactions with OLs are specific to discrete brain areas and cortical layers, and how these effects could affect ACC function at the computational level.

In conclusion, despite these limitations, our study suggests that the AS-OL GJ connectivity is decreased in the ACC of depressed suicides, possibly through decreased Cx30 coupling to OL- and myelin-specific connexins. This is associated with a convergent downregulation of key structural components and regulators of cell-cell junctions. Because AS/OL GJs play an important role in regulating $\mathrm{OL}$ cells development and function, we argue that our findings may relate to reported alterations of myelination observed in depressed suicides and further support glial dysfunction as a major hallmark of depression. Ultimately, as suggested by recent preclinical studies [54, 82, 123], targeting connexins and cell-cell junctions could prove useful in the search of novel therapeutic approaches for depression.

\section{FUNDING AND DISCLOSURE}

This research was funded by grants from CIHR (PJT-156346) and the AFSP (SRG-0-08815) to NM. AT was supported by a TD postdoctoral fellowship, and currently by an AFSP Young Investigator Innovation Grant (YIG-0-146-17). P-EL was supported by scholarships from the American Foundation of Suicide Prevention, the Fondation Deniker, the Fondation pour la Recherche Médicale, and the UNAFAM ("Union nationale de familles et amis de personnes malades et/ou handicapées psychiques"). The authors wish to thank the Douglas-Brain Canada Brain Bank (DBCBB) staff as well as the Douglas Institute's Molecular and Cellular Microscopy Platform coordinator for their precious assistance. Both of these research platforms are funded by a Core Facilities and Technology Development grant from Healthy Brains for Healthy Lives (CFREF). The DBCBB is further supported by the RQSHA (FRQ-S). The authors declare no competing interests.

\section{ADDITIONAL INFORMATION}

Supplementary Information accompanies this paper at (https://doi.org/10.1038/ s41386-019-0471-z)

Publisher's note: Springer Nature remains neutral with regard to jurisdictional claims in published maps and institutional affiliations.

\section{REFERENCES}

1. Miguel-Hidalgo JJ, Baucom C, Dilley G, Overholser JC, Meltzer HY, Stockmeier CA, et al. Glial fibrillary acidic protein immunoreactivity in the prefrontal cortex distinguishes younger from older adults in major depressive disorder. Biol Psychiatry. 2000;48:861-73.

2. Si X, Miguel-Hidalgo JJ, O'Dwyer G, Stockmeier CA, Rajkowska G. Age-dependent reductions in the level of glial fibrillary acidic protein in the prefrontal cortex in major depression. Neuropsychopharmacology. 2004;29:2088-96.

3. Rajkowska G, Hughes J, Stockmeier CA, Javier Miguel-Hidalgo J, Maciag D. Coverage of blood vessels by astrocytic endfeet is reduced in major depressive disorder. Biol Psychiatry. 2013;73:613-21.

4. Gittins RA, Harrison PJ. A morphometric study of glia and neurons in the anterior cingulate cortex in mood disorder. J Affect Disord. 2011;133:328-32.

5. Torres-Platas SG, Hercher C, Davoli MA, Maussion G, Labonté B, Turecki G, et al. Astrocytic hypertrophy in anterior cingulate white matter of depressed suicides. Neuropsychopharmacology. 2011;36:2650-8.

6. Torres-Platas SG, Nagy C, Wakid M, Turecki G, Mechawar N. Glial fibrillary acidic protein is differentially expressed across cortical and subcortical regions in healthy brains and downregulated in the thalamus and caudate nucleus of depressed suicides. Mol Psychiatry. 2016;21:509-15.

7. Nagy C, Torres-Platas SG, Mechawar N, Turecki G. Repression of astrocytic connexins in cortical and subcortical brain regions and prefrontal enrichment of 
H3K9me3 in depression and suicide. Int J Neuropsychopharmacol. 2016;20: pyw071.

8. Nagy C, Suderman M, Yang J, Szyf M, Mechawar N, Ernst C, et al. Astrocytic abnormalities and global DNA methylation patterns in depression and suicide. Mol Psychiatry. 2015;20:320-8.

9. Rajkowska G, Legutko B, Moulana M, Syed M, Romero DG, Stockmeier CA, et al. Astrocyte pathology in the ventral prefrontal white matter in depression. J Psychiatr Res. 2018;102:150-8.

10. Czéh B, Nagy SA. Clinical findings documenting cellular and molecular abnormalities of glia in depressive disorders. Front Mol Neurosci. 2018;11:56.

11. Leng L, Zhuang K, Liu Z, Huang C, Gao Y, Chen G, et al. Menin deficiency leads to depressive-like behaviors in mice by modulating astrocyte-mediated neuroinflammation. Neuron. 2018;100:551-63.e7.

12. Banasr M, Duman RS. Glial loss in the prefrontal cortex is sufficient to induce depressive-like behaviors. Biol Psychiatry. 2008;64:863-70.

13. Almeida RG, Lyons DA. On myelinated axon plasticity and neuronal circuit formation and function. J Neurosci. 2017;37:10023-34.

14. Gibson EM, Geraghty AC, Monje M. Bad wrap: myelin and myelin plasticity in health and disease. Dev Neurobiol. 2018;78:123-35.

15. Forbes TA, Gallo V. All wrapped up: environmental effects on myelination. Trends Neurosci. 2017;40:572-87.

16. Uranova NA, Vostrikov VM, Orlovskaya DD, Rachmanova VI. Oligodendroglial density in the prefrontal cortex in schizophrenia and mood disorders: a study from the Stanley Neuropathology Consortium. Schizophr Res. 2004;67:269-75.

17. Uranova N, Orlovskaya D, Vikhreva O, Zimina I, Kolomeets N, Vostrikov V, et al. Electron microscopy of oligodendroglia in severe mental illness. Brain Res Bull. 2001;55:597-610.

18. Lutz P-E, Tanti A, Gasecka A, Barnett-Burns S, Kim JJ, Zhou Y, et al. Association of a history of child abuse with impaired myelination in the anterior cingulate cortex: convergent epigenetic, transcriptional, and morphological evidence. Am J Psychiatry. 2017;174:appiajp201716111286.

19. Tanti A, Kim JJ, Wakid M, Davoli M-A, Turecki G, Mechawar N. Child abuse associates with an imbalance of oligodendrocyte-lineage cells in ventromedial prefrontal white matter. Mol Psychiatry. 2018;23:2018-28.

20. Hayashi Y, Nihonmatsu-Kikuchi N, Yu X, Ishimoto K, Hisanaga S, Tatebayashi Y. A novel, rapid, quantitative cell-counting method reveals oligodendroglial reduction in the frontopolar cortex in major depressive disorder. Mol Psychiatry. 2011;16:1156-8

21. Rajkowska G, Mahajan G, Maciag D, Sathyanesan M, lyo AH, Moulana $M$, et al. Oligodendrocyte morphometry and expression of myelin-related mRNA in ventral prefrontal white matter in major depressive disorder. J Psychiatr Res. 2015;65:53-62.

22. Edgar N, Sibille E. A putative functional role for oligodendrocytes in mood regulation. Transl Psychiatry. 2012;2:e109.

23. Aston C, Jiang L, Sokolov BP. Transcriptional profiling reveals evidence for signaling and oligodendroglial abnormalities in the temporal cortex from patients with major depressive disorder. Mol Psychiatry. 2005;10:309-22.

24. Kim S, Webster MJ. Correlation analysis between genome-wide expression profiles and cytoarchitectural abnormalities in the prefrontal cortex of psychiatric disorders. Mol Psychiatry. 2010;15:326-36.

25. Laine MA, Trontti K, Misiewicz Z, Sokolowska E, Kulesskaya N, Heikkinen A, et al. Genetic control of myelin plasticity after chronic psychosocial stress. eNeuro. 2018;5:ENEURO.0166-18.2018.

26. Gao Y, Ma J, Tang J, Liang X, Huang C-X, Wang S, et al. White matter atrophy and myelinated fiber disruption in a rat model of depression. J Comp Neurol. 2017;525:1922-33.

27. Miyata $S$, Taniguchi M, Koyama $Y$, Shimizu S, Tanaka T, Yasuno F, et al. Association between chronic stress-induced structural abnormalities in Ranvier nodes and reduced oligodendrocyte activity in major depression. Sci Rep. 2016;6:23084.

28. Tham MW, Woon PS, Sum MY, Lee T-S, Sim K. White matter abnormalities in major depression: evidence from post-mortem, neuroimaging and genetic studies. J Affect Disord. 2011;132:26-36.

29. Kim B, Oh J, Kim M-K, Lee S, Suk Tae W, Mo Kim C, et al. White matter alterations are associated with suicide attempt in patients with panic disorder. J Affect Disord. 2015;175C:139-46.

30. Peng $H$, Ning $Y$, Zhang $Y$, Yang $H$, Zhang $L$, He Z, et al. White-matter density abnormalities in depressive patients with and without childhood neglect: a voxel-based morphometry (VBM) analysis. Neurosci Lett. 2013;550:23-8.

31. Drevets WC, Price JL, Furey ML. Brain structural and functional abnormalities in mood disorders: implications for neurocircuitry models of depression. Brain Struct Funct. 2008;213:93-118.

32. Johansen-Berg H, Gutman DA, Behrens TEJ, Matthews PM, Rushworth MFS, Katz $\mathrm{E}$, et al. Anatomical connectivity of the subgenual cingulate region targeted with deep brain stimulation for treatment-resistant depression. Cereb Cortex. 2008;18:1374-83.

33. Steffens DC, Taylor WD, Denny KL, Bergman SR, Wang L. Structural integrity of the uncinate fasciculus and resting state functional connectivity of the ventral prefrontal cortex in late life depression. PLoS ONE. 2011;6:e22697.

34. Birn RM, Shackman AJ, Oler JA, Williams LE, McFarlin DR, Rogers GM, et al Evolutionarily conserved prefrontal-amygdalar dysfunction in early-life anxiety. Mol Psychiatry. 2014;19:915-22.

35. Koolschijn PCMP, van Haren NEM, Lensvelt-Mulders GJLM, Hulshoff Pol HE, Kahn RS. Brain volume abnormalities in major depressive disorder: a meta-analysis of magnetic resonance imaging studies. Hum Brain Mapp. 2009;30:3719-35.

36. Domingues HS, Portugal CC, Socodato R, Relvas JB. Oligodendrocyte, astrocyte, and microglia crosstalk in myelin development, damage, and repair. Front Cell Dev Biol. 2016;4:71.

37. Dutta DJ, Woo DH, Lee PR, Pajevic S, Bukalo O, Huffman WC, et al. Regulation of myelin structure and conduction velocity by perinodal astrocytes. Proc Natl Acad Sci USA. 2018;115:11832-7.

38. Kıray H, Lindsay SL, Hosseinzadeh S, Barnett SC. The multifaceted role of astrocytes in regulating myelination. Exp Neurol. 2016;283:541-9.

39. Li J, Zhang L, Chu Y, Namaka M, Deng B, Kong J, et al. Astrocytes in oligodendrocyte lineage development and white matter pathology. Front Cell Neurosci. 2016;10:119.

40. Nualart-Marti A, Solsona C, Fields RD. Gap junction communication in myelinating glia. Biochim Biophys Acta. 2013;1828:69-78.

41. Orthmann-murphy JL, Abrams CK, Scherer SS. Gap junctions couple astrocytes and oligodendrocytes. 2008. https://doi.org/10.1007/s12031-007-9027-5.

42. Evans WH, Martin PEM. Gap junctions: structure and function (Review). Mol Membr Biol. 2002;19:121-36.

43. Magnotti LM, Goodenough DA, Paul DL. Functional heterotypic interactions between astrocyte and oligodendrocyte connexins. Glia. 2011;59:26-34.

44. Maglione M, Tress O, Haas B, Karram K, Trotter J, Willecke K, et al. Oligodendrocytes in mouse corpus callosum are coupled via gap junction channels formed by connexin47 and connexin32. Glia. 2010;58:1104-17.

45. Nagy Jl, Rash JE. Connexins and gap junctions of astrocytes and oligodendrocytes in the CNS. Brain Res Brain Res Rev. 2000;32:29-44.

46. Rash JE, Yasumura T, Davidson KG, Furman CS, Dudek FE, Nagy J. Identification of cells expressing $\mathrm{C} \times 43, \mathrm{C} \times 30, \mathrm{C} \times 26, \mathrm{C} \times 32$ and $\mathrm{C} \times 36$ in gap junctions of rat brain and spinal cord. Cell Commun Adhes. 2001;8:315-20.

47. Orthmann-Murphy JL, Freidin M, Fischer E, Scherer SS, Abrams CK. Two distinct heterotypic channels mediate gap junction coupling between astrocyte and oligodendrocyte connexins. J Neurosci. 2007;27:13949-57.

48. Menichella DM, Goodenough DA, Sirkowski E, Scherer SS, Paul DL. Connexins are critical for normal myelination in the CNS. J Neurosci. 2003;23:5963-73.

49. Lutz SE, Zhao Y, Gulinello M, Lee SC, Raine CS, Brosnan CF. Deletion of astrocyte connexins 43 and 30 leads to a dysmyelinating phenotype and hippocampal CA1 vacuolation. J Neurosci. 2009;29:7743-52.

50. May D, Tress O, Seifert G, Willecke K. Connexin47 protein phosphorylation and stability in oligodendrocytes depend on expression of Connexin43 protein in astrocytes. J Neurosci. 2013;33:7985-96.

51. Tress O, Maglione M, May D, Pivneva T, Richter N, Seyfarth J, et al. Panglial gap junctional communication is essential for maintenance of myelin in the CNS. J Neurosci. 2012;32:7499-518.

52. Miguel-Hidalgo JJ, Wilson BA, Hussain S, Meshram A, Rajkowska G, Stockmeier CA. Reduced connexin 43 immunolabeling in the orbitofrontal cortex in alcohol dependence and depression. J Psychiatr Res. 2014;55:101-9.

53. Miguel-hidalgo J, Moulana M, Deloach PH, Rajkowska G. Chronic unpredictable stress reduces immunostaining for connexins 43 and 30 and myelin basic protein in the rat prelimbic and orbitofrontal cortices. 2018. https://doi.org/ $10.1177 / 2470547018814186$

54. Sun J-D, Liu Y, Yuan Y-H, Li J, Chen N-H. Gap junction dysfunction in the prefrontal cortex induces depressive-like behaviors in rats. Neuropsychopharmacology. 2012;37:1305-20.

55. Pannasch $\mathrm{U}$, Rouach $\mathrm{N}$. Emerging role for astroglial networks in information processing: from synapse to behavior. Trends Neurosci. 2013;36:405-17.

56. Dossi E, Vasile F, Rouach N. Human astrocytes in the diseased brain. Brain Res Bull. 2018:136:139-56

57. Rial D, Lemos C, Pinheiro H, Duarte JM, Gonçalves FQ, Real Jl, et al. Depression as a glial-based synaptic dysfunction. Front Cell Neurosci. 2016;9:521.

58. Teicher MH, Samson JA. Childhood maltreatment and psychopathology: a case for ecophenotypic variants as clinically and neurobiologically distinct subtypes. Am J Psychiatry. 2013;170:1114-33.

59. Tomassy GS, Berger DR, Chen H-H, Kasthuri N, Hayworth KJ, Vercelli A, et al. Distinct profiles of myelin distribution along single axons of pyramidal neurons in the neocortex. Science. 2014;344:319-24. 
60. Micheva KD, Chang EF, Nana AL, Seeley WW, Ting JT, Cobbs C et al. Distinctive structural and molecular features of myelinated inhibitory axons in human neocortex. eNeuro. 2018; 5. https://doi.org/10.1523/ENEURO.0297-18.2018.

61. Micheva KD, Wolman D, Mensh BD, Pax E, Buchanan J, Smith SJ et al. A large fraction of neocortical myelin ensheathes axons of local inhibitory neurons. Elife. 2016; 5. https://doi.org/10.7554/eLife.15784.

62. Dumais A, Lesage AD, Alda M, Rouleau G, Dumont M, Chawky N, et al. Risk factors for suicide completion in major depression: a case-control study of impulsive and aggressive behaviors in men. Am J Psychiatry. 2005;162:2116-24.

63. Bifulco A, Brown GW, Harris TO. Childhood Experience of Care and Abuse (CECA): a retrospective interview measure. J Child Psychol Psychiatry. 1994;35:1419-35.

64. Bifulco A, Brown GW, Lillie A, Jarvis J. Memories of childhood neglect and abuse: corroboration in a series of sisters. J Child Psychol Psychiatry. 1997;38:365-74.

65. Mai JK, Paxinos G, Voss T. Atlas of the human brain. Elsevier Acad. Press, Cambridge, Massachussets; 2008.

66. Laird DW. The gap junction proteome and its relationship to disease. Trends Cell Biol. 2010;20:92-101.

67. Singh D, Solan JL, Taffet SM, Javier R, Lampe PD. Connexin 43 interacts with zona occludens- 1 and -2 proteins in a cell cycle stage-specific manner. J Biol Chem. 2005;280:30416-21.

68. Martins-Marques T, Anjo SI, Pereira P, Manadas B, Girão H. Interacting network of the gap junction (GJ) protein connexin43 $(\mathrm{C} \times 43)$ is modulated by ischemia and reperfusion in the heart. Mol Cell Proteom. 2015;14:3040-55.

69. Giepmans B. Gap junctions and connexin-interacting proteins. Cardiovasc Res. 2004;62:233-45.

70. Dbouk HA, Mroue RM, El-Sabban ME, Talhouk RS. Connexins: a myriad of functions extending beyond assembly of gap junction channels. Cell Commun Signal. 2009;7:4.

71. Hunter AW, Barker RJ, Zhu C, Gourdie RG. Zonula occludens-1 alters connexin43 gap junction size and organization by influencing channel accretion. Mol Biol Cell. 2005; 16:5686-98.

72. Talhouk RS, Mroue R, Mokalled M, Abi-Mosleh L, Nehme R, Ismail A, et al. Heterocellular interaction enhances recruitment of $a$ and $\beta$-catenins and ZO-2 into functional gap-junction complexes and induces gap junction-dependant differentiation of mammary epithelial cells. Exp Cell Res. 2008;314:3275-91.

73. Majoul I, Shirao T, Sekino Y, Duden R. Many faces of drebrin: from building dendritic spines and stabilizing gap junctions to shaping neurite-like cell processes. Histochem Cell Biol. 2007;127:355-61.

74. Dianati E, Poiraud J, Weber-Ouellette A, Plante I. Connexins, E-cadherin, Claudin7 and $\beta$-catenin transiently form junctional nexuses during the post-natal mammary gland development. Dev Biol. 2016;416:52-68.

75. Kojima T, Sawada N, Chiba H, Kokai Y, Yamamoto M, Urban M, et al. Induction of tight junctions in human connexin 32 ( $\mathrm{hC} \times 32$ )-transfected mouse hepatocytes: connexin 32 interacts with occludin. Biochem Biophys Res Commun. 1999;266:222-9.

76. Kunzelmann P, Schröder W, Traub O, Steinhäuser C, Dermietzel R, Willecke K. Late onset and increasing expression of the gap junction protein connexin30 in adult murine brain and long-term cultured astrocytes. Glia. 1999;25:111-9.

77. Nagy Jl, Patel D, Ochalski PA, Stelmack GL. Connexin30 in rodent, cat and human brain: selective expression in gray matter astrocytes, co-localization with connexin43 at gap junctions and late developmental appearance. Neuroscience. 1999;88:447-68.

78. Ezan $P$, André $P$, Cisternino $S$, Saubaméa B, Boulay A-C, Doutremer $S$, et al. Deletion of astroglial connexins weakens the blood-brain barrier. J Cereb Blood Flow Metab. 2012;32:1457-67.

79. De Bock M, Vandenbroucke RE, Decrock $E$, Culot M, Cecchelli R, Leybaert L. A new angle on blood-CNS interfaces: a role for connexins? FEBS Lett. 2014;588:1259-70.

80. Rouach N, Koulakoff A, Abudara V, Willecke K, Giaume C. Astroglial metabolic networks sustain hippocampal synaptic transmission. Science. 2008;322:1551-5.

81. O'Leary L, Belliveau C, Davoli M-A, Mechawar N. Regional characterization of vimentin-immunoreactive astrocytes in the human brain. Program No. 042.01 Neuroscience Meeting Planner. San Diego, CA: Soceity for Neuroscience; 2018.

82. Jeanson T, Pondaven A, Ezan P, Mouthon F, Charvériat M, Giaume C. Antidepressants impact connexin 43 channel functions in astrocytes. Front Cell Neurosci. 2015;9:495

83. Kuhlmann T, Remington L, Maruschak B, Owens T, Brück W. Nogo-A is a reliable oligodendroglial marker in adult human and mouse CNS and in demyelinated lesions. J Neuropathol Exp Neurol. 2007;66:238-46.

84. Laird DW. Life cycle of connexins in health and disease. Biochem J. 2006;394:527-43.

85. Langlois S, Cowan KN, Shao Q, Cowan BJ, Laird DW. Caveolin-1 and -2 interact with connexin43 and regulate gap junctional intercellular communication in keratinocytes. Mol Biol Cell. 2008;19:912-28.
86. Butkevich E, Hülsmann S, Wenzel D, Shirao T, Duden R, Majoul I. Drebrin is a novel connexin-43 binding partner that links gap junctions to the submembrane cytoskeleton. Curr Biol. 2004;14:650-8.

87. Kojima T, Kokai Y, Chiba H, Yamamoto M, Mochizuki Y, Sawada N. Cx32 but not Cx26 is associated with tight junctions in primary cultures of rat hepatocytes. Exp Cell Res. 2001;263:193-201.

88. Fujimoto K, Nagafuchi A, Tsukita S, Kuraoka A, Ohokuma A, Shibata Y. Dynamics of connexins, E-cadherin and alpha-catenin on cell membranes during gap junction formation. J Cell Sci. 1997;110:311-22.

89. Denninger AR, Breglio A, Maheras KJ, LeDuc G, Cristiglio V, Demé B, et al. Claudin-11 tight junctions in myelin are a barrier to diffusion and lack strong adhesive properties. Biophys J. 2015;109:1387-97.

90. Gow A, Southwood CM, Li JS, Pariali M, Riordan GP, Brodie SE, et al. CNS myelin and sertoli cell tight junction strands are absent in Osp/claudin-11 null mice. Cell. 1999;99:649-59.

91. Morita K, Sasaki H, Fujimoto K, Furuse M, Tsukita S. Claudin-11/OSP-based tight junctions of myelin sheaths in brain and Sertoli cells in testis. J Cell Biol. 1999;145:579-88.

92. Schubert A-L, Schubert W, Spray DC, Lisanti MP. Connexin family members target to lipid raft domains and interact with caveolin-1. Biochemistry. 2002;41:5754-64.

93. Ursitti JA, Petrich BG, Lee PC, Resneck WG, Ye X, Yang J, et al. Role of an alternatively spliced form of alphall-spectrin in localization of connexin 43 in cardiomyocytes and regulation by stress-activated protein kinase. J Mol Cell Cardiol. 2007;42:572-81.

94. Toyofuku T, Yabuki M, Otsu K, Kuzuya T, Hori M, Tada M. Direct association of the gap junction protein connexin-43 with ZO-1 in cardiac myocytes. J Biol Chem. 1998;273:12725-31.

95. Duffy HS, Delmar M, Spray DC. Formation of the gap junction nexus: binding partners for connexins. J Physiol Paris. 2002;96:243-9.

96. Ernst C, Nagy C, Kim S, Yang JP, Deng X, Hellstrom IC, et al. Dysfunction of astrocyte connexins 30 and 43 in dorsal lateral prefrontal cortex of suicide completers. Biol Psychiatry. 2011;70:312-9.

97. Bronstein JM, Tiwari-Woodruff S. Tight Junctions in CNS Myelin. In: Lorenza González-Mariscal (ed) Tight Junctions. Boston, MA: Springer US; 2006, p. 196-205.

98. Brites D, Fernandes A. Neuroinflammation and depression: microglia activation, extracellular microvesicles and microRNA dysregulation. Front Cell Neurosci. 2015;9:476.

99. Torres-Platas SG, Cruceanu C, Chen GG, Turecki G, Mechawar N. Evidence for increased microglial priming and macrophage recruitment in the dorsal anterior cingulate white matter of depressed suicides. Brain Behav Immun. 2014:42:50-9.

100. Devorak J, Torres-Platas SG, Davoli MA, Prud'homme J, Turecki G, Mechawar N. Cellular and molecular inflammatory profile of the choroid plexus in depression and suicide. Front Psychiatry. 2015; 6. https://doi.org/10.3389/fpsyt.2015.00138.

101. Rochfort KD, Cummins PM. Cytokine-mediated dysregulation of zonula occludens-1 properties in human brain microvascular endothelium. Micro Res. 2015;100:48-53.

102. Van Itallie CM, Fanning AS, Holmes J, Anderson JM. Occludin is required for cytokine-induced regulation of tight junction barriers. J Cell Sci. 2010;123:2844-52.

103. Capaldo CT, Farkas AE, Hilgarth RS, Krug SM, Wolf MF, Benedik JK, et al. Proinflammatory cytokine-induced tight junction remodeling through dynamic self-assembly of claudins. Mol Biol Cell. 2014;25:2710-9.

104. Menard C, Pfau ML, Hodes GE, Kana V, Wang VX, Bouchard S, et al. Social stress induces neurovascular pathology promoting depression. Nat Neurosci. 2017;20:1752-60.

105. Castellano $P$, Eugenin EA. Regulation of gap junction channels by infectious agents and inflammation in the CNS. Front Cell Neurosci. 2014;8:122.

106. Olympiou M, Sargiannidou I, Markoullis K, Karaiskos C, Kagiava A, Kyriakoudi S, et al. Systemic inflammation disrupts oligodendrocyte gap junctions and induces ER stress in a model of CNS manifestations of X-linked Charcot-MarieTooth disease. Acta Neuropathol Commun. 2016;4:95.

107. Papaneophytou CP, Georgiou E, Karaiskos C, Sargiannidou I, Markoullis K, Freidin $\mathrm{MM}$, et al. Regulatory role of oligodendrocyte gap junctions in inflammatory demyelination. Glia. 2018;66:2589-603.

108. Markoullis K, Sargiannidou I, Schiza N, Hadjisavvas A, Roncaroli F, Reynolds R, et al. Gap junction pathology in multiple sclerosis lesions and normal-appearing white matter. Acta Neuropathol. 2012;123:873-86.

109. Markoullis K, Sargiannidou I, Schiza N, Roncaroli F, Reynolds R, Kleopa KA. Oligodendrocyte gap junction loss and disconnection from reactive astrocytes in multiple sclerosis gray matter. J Neuropathol Exp Neurol. 2014;73:865-79.

110. Drevets WC, Savitz J, Trimble M. The subgenual anterior cingulate cortex in mood disorders. CNS Spectr. 2008;13:663-81. 
111. Teicher $\mathrm{MH}$, Samson Ja, Anderson CM, Ohashi K. The effects of childhood maltreatment on brain structure, function and connectivity. Nat Rev Neurosci. 2016;17:652-66.

112. Labonté B, Engmann O, Purushothaman I, Menard C, Wang J, Tan C, et al. Sexspecific transcriptional signatures in human depression. Nat Med. 2017;23: 1102-11.

113. Seney ML, Huo Z, Cahill K, French L, Puralewski R, Zhang J, et al. Opposite molecular signatures of depression in men and women. Biol Psychiatry. 2018;84: 18-27.

114. Sterrenburg L, Gaszner B, Boerrigter J, Santbergen L, Bramini M, Elliott E, et al. Chronic stress induces sex-specific alterations in methylation and expression of corticotropin-releasing factor gene in the rat. PLoS ONE. 2011;6: e28128.

115. DeSantis SM, Baker NL, Back SE, Spratt E, Ciolino JD, Moran-Santa Maria M, et al. Gender differences in the effect of early life trauma on hypothalamicpituitary-adrenal axis functioning. Depress Anxiety. 2011;28:383-92.

116. Asscher JJ, Van der Put CE, Stams GJJM. Gender differences in the impact of abuse and neglect victimization on adolescent offending behavior. J Fam Violence. 2015;30:215-25.
117. Mueller BR, Bale TL. Sex-specific programming of offspring emotionality after stress early in pregnancy. J Neurosci. 2008;28:9055-65.

118. Wellman CL, Bangasser DA, Bollinger JL, Coutellier L, Logrip ML, Moench KM, et al. Sex differences in risk and resilience: stress effects on the neural substrates of emotion and motivation. J Neurosci. 2018;38:9423-32.

119. Schwarz JM, Bilbo SD. Sex, glia, and development: interactions in health and disease. Horm Behav. 2012;62:243-53.

120. Chowen JA, Busiguina S, García-Segura LM. Sexual dimorphism and sex steroid modulation of glial fibrillary acidic protein messenger RNA and immunoreactivity levels in the rat hypothalamus. Neuroscience. 1995;69:519-32.

121. Swamydas M, Bessert D, Skoff R. Sexual dimorphism of oligodendrocytes is mediated by differential regulation of signaling pathways. J Neurosci Res. 2009:87:3306-19.

122. Cerghet M, Skoff RP, Bessert D, Zhang Z, Mullins C, Ghandour MS. Proliferation and death of oligodendrocytes and myelin proteins are differentially regulated in male and female rodents. J Neurosci. 2006;26:1439-47.

123. Sarrouilhe D, Mesnil M, Dejean C. Targeting gap junctions: new insights in the treatment of major depressive disorder. Curr Med Chem. 2018; 25. https://doi. org/10.2174/0929867325666180327103530. 